\title{
Heavy cannabis users at elevated risk of stroke: evidence from a general population survey
}

\author{
Dilini Hemachandra, ${ }^{1,2}$ Rebecca McKetin, ${ }^{2}$ Nicolas Cherbuin, ${ }^{2}$ Kaarin J. Anstey ${ }^{2}$
}

W ith many countries broaching the issue of legalising cannabis, understanding whether the drug is a risk factor for stroke is critical. ${ }^{1}$ Already, cannabis is consumed by an estimated 181 million people worldwide, ${ }^{2}$ with 13.1 million dependent on the drug. ${ }^{3}$ Cannabis use is projected to rise significantly in older cohorts (50+ years) with the ageing of the baby boomer generation, ${ }^{4}$ making it a potentially modifiable risk fact for stroke.

Numerous case studies underscore the potential link between cannabis use and stroke, ${ }^{1,5}$ this being more commonly seen in heavier cannabis users, and precipitated by unusually large doses of cannabis, concurrent alcohol intoxication, or exercise. ${ }^{6}$ Cannabis intoxication is postulated to increase the risk of stroke via orthostatic hypotension. ${ }^{\text {? }}$ Other cardiovascular anomalies found in chronic cannabis users could also increase stroke risk, these including diminished circulatory response to exercise, ${ }^{7}$ cerebral vasoconstriction, ${ }^{6}$ intracranial stenosis, ${ }^{6}$ increased cerebrovascular resistance and reduced cerebrovascular perfusion. ${ }^{8}$

Only two studies have attempted to quantify the relationship between cannabis use and stroke risk at a population level. Westover et al. ${ }^{9}$ demonstrated an elevated rate of ischemic stroke among cannabis users entering hospital. More recently, Barber et al..$^{10}$ conducted a case-control study showing greater rates of cannabis use among stroke patients in hospital than in a control population, but this association was not significant after controlling for tobacco smoking. Heavy drinking, which occurs disproportionately more often among heavy

\begin{abstract}
Objective: Case reports and hospital-based case-control studies suggest that cannabis use may increase the risk of stroke. We examined the risk of non-fatal stroke or transient ischemic attack (TIA) among cannabis users in the general community.

Method: A general population survey of Australians aged $20-24$ years $(n=2,383), 40-44$ years $(n=2,525)$ and $60-64$ years $(n=2,547)$ was used to determine the odds of lifetime stroke or TIA among participants who had smoked cannabis in the past year while adjusting for other stroke risk factors.

Results: There were 153 stroke/TIA cases (2.1\%). After adjusting for age cohort, past year cannabis users $(n=1,043)$ had 3.3 times the rate of stroke/TIA $(95 \% \mathrm{Cl} 1.8-6.3, p<0.001)$. The incidence rate ratio (IRR) reduced to 2.3 after adjustment for covariates related to stroke, including tobacco smoking (95\% Cl 1.1-4.5). Elevated stroke/TIA was specific to participants who used cannabis weekly or more often (IRR 4.7, 95\% Cl 2.1-10.7) with no elevation among participants who used cannabis less often.
\end{abstract}

Conclusions: Heavy cannabis users in the general community have a higher rate of non-fatal stroke or transient ischemic attack than non-cannabis users.

Key words: cannabis, stroke, transient ischemic attack, substance-related disorders

cannabis users, is also a known risk factor for stroke. ${ }^{11}$ No studies have examined whether cannabis users in the general population have a higher risk of stroke than non-cannabis users.

We examine the relationship between cannabis use and non-fatal stroke or transient ischemic (TIA) attack in a large general population sample. We also examine whether this relationship is better accounted for by tobacco smoking, heavy alcohol consumption and a range of other risk factors for stroke.

\section{Methods}

\section{Participants and procedure}

Data were taken from the baseline phase of the Personality and Total Health (PATH)
Through Life study, ${ }^{12}$ a longitudinal cohort study of participants who were recruited at ages 20-24 years (20s), 40-44 years (40s), and 60-64 years (60s) in 1999-2000, 20002001 and 2001-2002, respectively. PATH participants were randomly drawn from the electoral roll of the Australian Capital Territory and the nearby city of Queanbeyan in Australia. Voting is compulsory in Australia; therefore, electoral role samples provide a good reflection of the adult general population. Comparison with the Australian census data show that the cohort are representative of the general population in terms of their marital and employment status but that they are more educated..$^{12}$ There was a $65 \%$ participation rate, giving 2,404 participants in the 20s; 2,530 participants

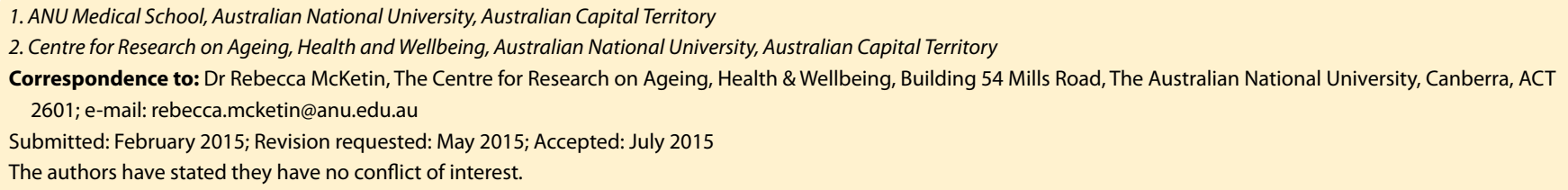


in the 40s; and 2,551 participants in the 60s. Interviews were self-completed using a computer and were conducted in person and, in rare cases, by mail. Data on cannabis use and stroke/TIA were missing for 28 and 2 participants respectively, giving a final sample of 7,455 .

All participants were volunteers who provided informed consent prior to participation. The study was approved by the Australian National University's Human Research Ethics Committee.

\section{Measures}

The PATH questionnaire collects a broad range of data on demographics, health and well-being. Stroke was assessed using the question, "Have you ever suffered a stroke, ministroke or TIA (Transient Ischemic Attack)?" Past year cannabis use was assessed using the question "Have you used marijuana/ hash in the past 12 months?" followed by the question "How often do you use marijuana/ hash?" (once a week or more, once a month, every 1-4 months, once or twice a year, less often/no longer use). Tobacco smoking was classified as never smoked, current smoker and past smoker. Risky alcohol consumption was defined as a score of $8+$ on the Alcohol Use Disorders Identification Test (AUDIT). ${ }^{13}$ Body mass index (BMI) was calculated using self-reported height and weight [weight $(\mathrm{kg}) /$ height $\left.(\mathrm{m})^{2}\right]$ and used to identify participants who were overweight (BMI 25 to $<30$ ) and obese (BMI 30+). Systolic/diastolic blood pressure were based on the average of two measurements taken from the upper arm using an Omron M4 monitor after the participant was seated for at least five minutes. Hypertension was defined as a mean diastolic or systolic blood pressure above $90 \mathrm{mmHg}$ and $140 \mathrm{mmHg}$, respectively, or self-reported use of anti-hypertensive medication. Other health conditions were assessed by asking participants, "Here is a list of medical problems. Do you have any of the following?" and presenting a list of eight health conditions including "heart trouble" and "diabetes". Frequency of exercise, and the use of oral contraception and hormone replacement therapy (HRT), were based on self-report. Examples of mild exercise were: walking, woodwork, weeding, hoeing, bicycle repair, playing pool, general housework; moderate exercise: scrubbing, polishing car, dancing, golf, cycling, decorating, lawn mowing, leisurely swimming; and vigorous exercise: running, hard swimming, tennis, squash, digging, cycle racing.

\section{Statistical analysis}

Analyses were conducted using Stata Special Edition version 11.2 (Statacorp, College Station, TX). Descriptive comparisons were made with a Pearson's chi square test. The rate of stroke per 100 persons and $95 \%$ confidence intervals $(95 \% \mathrm{Cl})$ were calculated using a Poisson distribution due to the low prevalence of stroke and large sample size. ${ }^{14}$ Poisson regression models were used to estimate rate ratios while adjusting for variables associated with stroke. Missing data for variables (range $0-36$ cases, or $<0.5 \%$ ) were assumed to be missing at random and excluded from the analysis. All tests were twosided with significance set at $p<0.05$.

\section{Results}

Participants were mostly English-speaking Caucasians who were employed; $15 \%$ were obese, $21 \%$ were hypertensive and $20 \%$ smoked tobacco (Table 1). Fourteen per cent $(n=1,043)$ had used cannabis in the past year,

\begin{tabular}{|c|c|c|c|c|}
\hline & \multicolumn{2}{|c|}{ Past year cannabis use } & \multirow{2}{*}{ Total $(\mathrm{N}=7,455)$} & \multirow{2}{*}{$p$ value } \\
\hline & No $(n=6,412)$ & Yes $(n=1,043)$ & & \\
\hline Age cohort, $\mathrm{n}(\%)$ & & & & $<0.001$ \\
\hline $20 \mathrm{~s}$ & $1,579(25 \%)$ & $804(77 \%)$ & $2,404(32 \%)$ & \\
\hline $40 \mathrm{~s}$ & $2,305(36 \%)$ & $222(21 \%)$ & $2,530(34 \%)$ & \\
\hline $60 \mathrm{~s}$ & $2,529(39 \%)$ & $18(2 \%)$ & $2,551(34 \%)$ & \\
\hline Male, $\mathrm{n}(\%)$ & $3,046(48 \%)$ & $612(59 \%)$ & $3,672(49 \%)$ & $<0.001$ \\
\hline Ethnicity, n (\%) & & & & $<0.001$ \\
\hline Caucasian & $6,038(94 \%)$ & $982(94 \%)$ & $7,023(94 \%)$ & \\
\hline Asian & $212(3 \%)$ & $18(2 \%)$ & $232(3 \%)$ & \\
\hline Other & $162(3 \%)$ & $43(4 \%)$ & $205(3 \%)$ & \\
\hline Employed, n (\%) & $4,461(70 \%)$ & $880(84 \%)$ & $5,341(72 \%)$ & $<0.001$ \\
\hline Completed high school, n (\%) & $4,484(70 \%)$ & $869(83 \%)$ & $5,353(72 \%)$ & $<0.001$ \\
\hline Tertiary education, n (\%) & & & & $<0.001$ \\
\hline None & 1,889 (29\%) & 477 (46\%) & 2,366 (32\%) & \\
\hline Non-university & $2,366(37 \%)$ & $349(33 \%)$ & $2,715(36 \%)$ & \\
\hline University & $2,157(34 \%)$ & $218(21 \%)$ & $2,375(32 \%)$ & \\
\hline Tobacco smoking, n (\%) & & & & $<0.001$ \\
\hline Never & $3,653(57 \%)$ & $319(30 \%)$ & $3,973(53 \%)$ & \\
\hline Past & $1,801(28 \%)$ & $176(17 \%)$ & $1,978(27 \%)$ & \\
\hline Current & $957(15 \%)$ & $549(53 \%)$ & $1,507(20 \%)$ & \\
\hline Risky alcohol consumption ${ }^{\mathrm{a}}, \mathrm{n}(\%)$ & $940(15 \%)$ & $515(49 \%)$ & $1,456(20 \%)$ & $<0.001$ \\
\hline Body mass index, $\mathrm{n}(\%)$ & & & & $<0.001$ \\
\hline $0-24.9$ & $2,992(50 \%)$ & $644(65 \%)$ & $3,638(52 \%)$ & \\
\hline $25-29.9$ & $1,998(33 \%)$ & $259(26 \%)$ & $2,257(32 \%)$ & \\
\hline$>30$ & $982(16 \%)$ & $88(9 \%)$ & $1,070(15 \%)$ & \\
\hline Hypertension, n (\%) & $2,342(37 \%)$ & $184(18 \%)$ & $2,526(34 \%)$ & $<0.001$ \\
\hline Diabetes, n (\%) & $249(4 \%)$ & $7(1 \%)$ & $256(3 \%)$ & $<0.001$ \\
\hline Heart trouble, n (\%) & $463(7 \%)$ & $27(3 \%)$ & $490(7 \%)$ & $<0.001$ \\
\hline Contraceptive use $^{\mathrm{b}}, \mathrm{n}(\%)$ & $659(20 \%)$ & $194(45 \%)$ & $853(22 \%)$ & $<0.001$ \\
\hline $\mathrm{HRT}^{\mathrm{b}}, \mathrm{n}(\%)$ & $865(26 \%)$ & $12(3 \%)$ & $877(23 \%)$ & $<0.001$ \\
\hline Mild exercise, n (\%) & & & & $<0.001$ \\
\hline None to < weekly & $812(13 \%)$ & $161(15 \%)$ & $973(13 \%)$ & \\
\hline 1-2/weekly & $1,561(24 \%)$ & $288(28 \%)$ & $1,849(25 \%)$ & \\
\hline 3+ weekly & $4,010(63 \%)$ & $589(57 \%)$ & $4,599(62 \%)$ & \\
\hline Moderate exercise, n (\%) & & & & 0.007 \\
\hline None to < weekly & $2,062(32 \%)$ & $291(28 \%)$ & $2,353(32 \%)$ & \\
\hline 1-2/weekly & $2,404(38 \%)$ & $393(38 \%)$ & $2,797(38 \%)$ & \\
\hline 3+ weekly & $1,918(30 \%)$ & $354(34 \%)$ & $2,272(31 \%)$ & \\
\hline Vigorous exercise, n (\%) & & & & $<0.001$ \\
\hline None to < weekly & $4,303(67 \%)$ & $579(56 \%)$ & $4,882(66 \%)$ & \\
\hline 1-2/weekly & $1,135(18 \%)$ & $254(24 \%)$ & $1,389(19 \%)$ & \\
\hline $3+$ weekly & $946(15 \%)$ & $204(20 \%)$ & $1,150(16 \%)$ & \\
\hline
\end{tabular}


$30 \%$ of whom $(n=313)$ had used weekly or more often. Compared to other participants, past year cannabis users were much younger and differed on all other covariates, including being more likely to smoke tobacco (Table 1).

There were 153 cases of stroke/TIA in the cohort (2.1 per 100 persons), these being far more common in the older age cohorts, with 6 cases in the 20s, 31 cases in the 40s (IRR 4.9 cf. the 20s cohort, $p<0.001$ ) and 116 cases in the 60s (IRR $18.1 \mathrm{cf}$. the 20s cohort, $p<0.001)$. After adjusting for age cohort, past year cannabis users were three times more likely to report stroke/TIA (Table 2). Increased risk of stroke/TIA was also related to tobacco smoking, heart trouble, diabetes and hypertension, while exercise, tertiary education and employment were protective (Table 2). Risky alcohol consumption was not related to the risk of stroke/TIA in this sample (Table 2).

Table 3 shows the relationship between stroke/TIA and cannabis use with three progressive models of confounder adjustment. First, we adjusted only for demographic confounders (model 1), then we added other substance use variables (model 2), prior health conditions (model 3) and finally exercise (model 4). Covariates were only included if they were significantly associated with stroke/TIA after adjustment for age cohort (see Table 2). All of these covariates were retained in the final model. All models adjusted for age cohort (i.e. whether the participant was in the $20 \mathrm{~s}, 40 \mathrm{~s}$ or $60 \mathrm{~s}$ cohort) and sex.

The relationship between cannabis use and stroke/TIA persisted after adjustment for demographics (model 1), tobacco smoking (model 2) and health conditions that were related to stroke/TIA risk; namely, hypertension, heart problems and diabetes (model 3). After adjustment for all of these variables and exercise, past year cannabis users had 2.3 times the risk of stroke/TIA compared to participants who had not smoked cannabis in the past year (model 4).

Adjusting for covariates in model 4, we found that using cannabis less than weekly in the past year was not associated with a significant increase in the risk of stroke/TIA relative to no cannabis use in the past year (adjusted IRR 1.2, 95\%Cl 0.4-3.4, $p=0.77$ ); whereas, using cannabis weekly or more often was associated with almost a five-fold increase in the risk of stroke/TIA (adjusted IRR $4.7,95 \% \mathrm{CI}$ 2.1-10.7, $p<0.001)$.
Table 2: Lifetime stroke/TIA by participant characteristics.

Sample (n) $\begin{array}{cccc}\text { Cases of } & \text { Mean rate per } 100 & \text { Adjusted for age } & p \text { value } \\ & \text { stroke }(\mathrm{n}) & \text { persons }(95 \% \text { (I) } & \text { cohot }\end{array}$

\section{Past year cannabis use}

$\begin{array}{lrrrrr}\text { No } & 6,412 & 139 & 2.2(1.8-2.6) & \text { Ref. } & \\ \text { Yes } & 1,043 & 14 & 1.3(0.7-2.3) & 3.3(1.8-6.3) & <0.001\end{array}$

Sex

$\begin{array}{lllll}\text { Male } & 3,656 & 84 & 2.3(1.8-2.8) & \text { Ref. }\end{array}$

$\begin{array}{llllrr}\text { Male } & 3,656 & 84 & 2.3(1.8-2.8) & \text { Ref. } & \\ \text { Female } & 3,799 & 69 & 1.8(1.4-2.3) & 0.8(0.6-1.2) & 0.282\end{array}$

Ethnicity

$\begin{array}{lllll}\text { Caucasian } & 7018 & 146 & 2.1(1.8-2.4) & \text { Ref. }\end{array}$

Completed high school

$\begin{array}{lllll}\text { No } & 2,102 & 63 & 3.0(2.3-3.8) & \text { Ref. }\end{array}$

$\begin{array}{llllll}\text { Yes } & 5,352 & 90 & 1.7(1.4-2.1) & 1.0(0.7-1.4) & 0.951\end{array}$

\section{Tertiary education}

$\begin{array}{llllr}\text { None } & 2,364 & 54 & 2.3(1.7-3.0) & \text { Ref. }\end{array}$

$\begin{array}{llllll}\text { Non-university } & 2,715 & 60 & 2.2(1.7-2.8) & 0.7(0.5-1.0) & 0.068\end{array}$

$\begin{array}{llllll}\text { University } & 2,375 & 39 & 1.6(1.2-2.2) & 0.6(0.4-0.9) & 0.011\end{array}$

Employed

$\begin{array}{llllrl}\text { No } & 2,114 & 96 & 4.5(3.7-5.5) & \text { Ref. } & \\ \text { Yes } & 5,340 & 57 & 1.1(0.8-1.4) & 0.5(0.3-0.7) & <0.001\end{array}$

Tobacco smoking

$\begin{array}{llll}\text { Never } & 3.972 & 66 & 1.7(1.3-2.1)\end{array}$

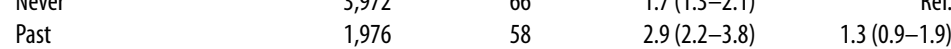

Current 1,505

Risky alcohol consumption ${ }^{\mathrm{a}}$

$\begin{array}{lllll}\text { No } & 5,989 & 131 & 2.2(1.8-2.6) & \text { Ref. }\end{array}$

$\begin{array}{llllll}\text { Yes } & 1,455 & 22 & 1.5(0.9-2.3) & 1.2(0.8-1.9) & 0.409\end{array}$

Hypertension
No
Yes

$\begin{array}{llllll}\text { Yes } & 2,526 & 98 & 3.9(3.1-4.7) & 1.7(1.2-2.4) & 0.004\end{array}$

\section{Body mass index}

$\begin{array}{lllll}0-24.9 & 3,636 & 60 & 1.7(1.3-2.1) & \text { Ref. }\end{array}$

$>30 \quad 1,070$

Heart trouble

$\begin{array}{lrrrrr}\text { No } & 6,960 & 100 & 1.4(1.2-1.7) & \text { Ref. } & \\ \text { Yes } & 490 & 53 & 10.8(8.1-14.1) & 4.1(2.9-5.9) & <0.001\end{array}$

\section{Diabetes}

No 7,199

Yes

Oral contraception ${ }^{\mathrm{b}}$

Oral contraception
No
Yes

$\begin{aligned} \text { HRT }^{\text {b }} & \\ \text { No } & 2,916 \\ \text { Yes } & \end{aligned}$

Yes

None to < weekly

$1-2 /$ weekly

$3+$ weekly

Moderate exercise

None to <weekly

1-2/weekly

$3+$ weekly

256

$1.9(1.6-2.2)$

$6.3(3.6-10.0)$

Ref.

$\begin{array}{lll}256 & 6.3(3.6-10.0) & \text { Ref. }\end{array}$

0.029

Vigorous exercise

None to <weekly

$1-2 /$ weekly

$3+$ weekly

$\begin{array}{llll}2,941 & 67 & 2.3(1.8-2.9) & \text { Ref. }\end{array}$

$\begin{array}{llll}2 & 0.2(0.0-0.8) & 0.6(0.1-2.8) & 0.5\end{array}$

a AUDIT score 8

bWomen only; Hormone replacement therapy (HRT)

$1.2(0.8-1.6) \quad$ Ref.

$\begin{array}{rrrrr}9916 & 34 & 1.2(0.8-1.6) & \text { Ref. } \\ 877 & 35 & 4.0(2.8-5.6) & 0.9(0.6-1.6) & 0.818\end{array}$

.542 


\section{Description of cannabis users who reported stroke}

In total, there were 14 cases of non-fatal stroke or TIA among participants who had used cannabis in the past year. The characteristics of these participants are shown in Table 4. Most were in their 40s and using cannabis weekly or more often, and they also smoked tobacco. Other comorbidities suggestive of metabolic syndrome (obesity, hypertension, heart trouble) were found in around half of the cases, including those cases involving infrequent cannabis use, potentially predisposing these participants to stroke/TIA. Although several participants had AUDIT scores suggestive of an alcohol use disorder, the frequency of heavy drinking occasions (assessed as $6+$ drinks per occasion on the AUDIT) was reflective of episodic heavy drinking (or 'binge' drinking), with the exception of one participant in the 60s age cohort who was drinking heavily on a daily basis. There were three cases of stroke in the 20 s age cohort, all of which occurred in men who smoked tobacco: two appeared to have problematic levels of cannabis use, and the third had ceased use.

\section{Discussion}

These findings indicate that heavy cannabis users are at an elevated risk for stroke.

They add to a growing body of evidence suggesting a relationship between cannabis use and stroke risk. This evidence includes cases of stroke among cannabis users that appear to be mediated by cannabis-related changes in cerebrovascular function. 'It has also included case-control studies showing that cannabis use is associated with elevated rates of stroke in a hospital setting..$^{910}$ Our results extend this body of

\begin{tabular}{|c|c|c|c|c|c|c|c|}
\hline \multirow[b]{2}{*}{$\begin{array}{l}\text { Age } \\
\text { group }\end{array}$} & \multirow[b]{2}{*}{ Sex } & \multicolumn{2}{|c|}{ Cannabis use } & \multirow[b]{2}{*}{ Comorbidities $^{\mathrm{a}}$} & \multirow[b]{2}{*}{$\begin{array}{l}\text { Tobacco } \\
\text { smoking }\end{array}$} & \multirow{2}{*}{$\begin{array}{l}\text { Alcohol use } \\
\text { disorder risk } \\
\text { (AUDIT score 8+) }\end{array}$} & \multirow{2}{*}{$\begin{array}{l}\text { Frequency of heavy } \\
\text { drinking ( } 6+\text { drinks } \\
\text { on one occasion) }\end{array}$} \\
\hline & & $\begin{array}{l}\text { Current } \\
\text { frequency of use }\end{array}$ & $\begin{array}{l}\text { Felt need to } \\
\text { cut-down }\end{array}$ & & & & \\
\hline \multirow[t]{3}{*}{$20-24$ yrs } & M & Weekly+ & Yes & \multirow[t]{3}{*}{ Obesity } & Current & Yes & Weekly \\
\hline & M & Weekly+ & Yes & & Current & Yes & $<$ monthly \\
\hline & M & No longer using & No & & Current & No & Monthly \\
\hline \multirow[t]{9}{*}{$40-44$ yrs } & $\mathrm{F}$ & Weekly+ & Yes & \multirow[t]{2}{*}{ Hypertension } & Current & No & $<$ monthly \\
\hline & $M$ & Weekly+ & No & & Past & Yes & $<$ monthly \\
\hline & $\mathrm{F}$ & $1-2$ times/past yr & No & $\begin{array}{l}\text { Obesity, heart } \\
\text { trouble }\end{array}$ & Current & Yes & Weekly \\
\hline & M & Weekly+ & No & $\begin{array}{l}\text { Hypertension, } \\
\text { overweight, heart } \\
\text { trouble }\end{array}$ & Current & No & Non-drinker \\
\hline & M & $1-2$ times/past yr & No & \multirow[t]{3}{*}{ Heart trouble } & Current & Yes & Weekly \\
\hline & M & Weekly+ & Yes & & Current & Yes & Monthly \\
\hline & $F$ & No longer using & No & & Never & No & Never \\
\hline & M & Weekly+ & Yes & \multirow[t]{2}{*}{ Heart trouble } & Current & Yes & Monthly \\
\hline & M & Weekly+ & No & & Current & No & Non-drinker \\
\hline \multirow[t]{2}{*}{$60-64$ yrs } & $M$ & Weekly+ & No & Hypertension & Current & No & $<$ monthly \\
\hline & M & $1-2$ times/past yr & No & Obesity & Current & Yes & Daily/almost daily \\
\hline
\end{tabular}

a: None had diabetes; the three female participants had used contraceptives in the past but not currently. All participants reported using cannabis in the past year.

Table 3: Models examining the relationship between cannabis use and stroke adjusting for other participant characteristics.

\begin{tabular}{|c|c|c|c|c|c|c|c|c|}
\hline & \multicolumn{2}{|c|}{ Model 1} & \multicolumn{2}{|c|}{ Model 2} & \multicolumn{2}{|c|}{ Model 3} & \multicolumn{2}{|c|}{ Model 4} \\
\hline & IRR (95\% Cl) & $P$ value & IRR (95\% Cl) & $P$ value & IRR (95\% Cl) & $P$ value & IRR (95\% Cl) & $P$ value \\
\hline \multicolumn{9}{|l|}{ Tertiary } \\
\hline None & Ref. & & Ref. & & Ref. & & & \\
\hline Non-university & $0.8(0.5-1.1)$ & 0.135 & $0.8(0.5-1.1)$ & 0.145 & $0.8(0.5-1.1)$ & 0.134 & $0.7(0.5-1.1)$ & 0.105 \\
\hline Employed & $0.5(0.3-0.7)$ & $<0.001$ & $0.5(0.3-0.7)$ & $<0.001$ & $0.6(0.4-0.8)$ & 0.003 & $0.5(0.4-0.8)$ & 0.002 \\
\hline \multicolumn{9}{|l|}{ Tobacco smoking } \\
\hline Never & & & Ref. & & Ref. & & & \\
\hline Past & & & $1.2(0.8-1.7)$ & 0.345 & $1.1(0.7-1.5)$ & 0.748 & $1.0(0.7-1.5)$ & 0.999 \\
\hline Current & & & $1.4(0.9-2.2)$ & 0.194 & $1.3(0.8-2.1)$ & 0.239 & $1.2(0.7-2.0)$ & 0.423 \\
\hline Hypertension & & & & & $1.5(1.0-2.1)$ & 0.048 & $1.5(1.0-2.1)$ & 0.047 \\
\hline Heart trouble & & & & & $3.5(2.5-5.1)$ & $<0.001$ & $3.5(2.5-5.1)$ & $<0.001$ \\
\hline \multicolumn{9}{|l|}{ Mild exercise } \\
\hline None to < weekly & & & & & & & Ref. & \\
\hline 1-2/weekly & & & & & & & $0.6(0.4-1.1)$ & 0.079 \\
\hline 3+ weekly & & & & & & & $0.6(0.4-1.0)$ & 0.035 \\
\hline \multicolumn{9}{|l|}{ Moderate exercise } \\
\hline None to < weekly & & & & & & & Ref. & \\
\hline 1-2/weekly & & & & & & & $0.7(0.5-1.1)$ & 0.087 \\
\hline 3+ weekly & & & & & & & $0.7(0.4-1.1)$ & 0.097 \\
\hline \multicolumn{9}{|l|}{ Vigorous exercise } \\
\hline None to < weekly & & & & & & & Ref. & \\
\hline 1-2/weekly & & & & & & & $0.7(0.4-1.4)$ & 0.311 \\
\hline $3+$ weekly & & & & & & & $1.7(0.9-3.0)$ & 0.083 \\
\hline
\end{tabular}


evidence by showing that the association between cannabis use and stroke risk also exists among cannabis users in the general community. Furthermore, we show that this association does not seem to be due to tobacco smoking among cannabis users, that it persists after adjustment for various other lifestyle risk factors for stroke, and that it appears to be specific to smoking cannabis weekly or more often.

Being a cross-sectional study, we cannot infer a causal relationship between stroke and cannabis use; however, our study does demonstrate the presence of this association at a population level, and it does suggest that this association is not due to tobacco smoking and a range of other risk factors for stroke that exist among cannabis users. The low number of stroke/TIA cases in this cohort, particularly among heavy cannabis users, indicates a need to replicate these findings in other cohorts, possibly combining data from multiple population cohorts to improve the robustness of findings. The findings are also limited to non-fatal stroke risk among a predominantly Caucasian population.

The strength of our findings is that they are based on a large general population sample and we were able to adjust for a wide variety of lifestyle and health factors that were related to stroke/TIA. The PATH cohort provides a unique opportunity to examine the relationship between cannabis use and stroke because it includes older adults; whereas, other cannabis research has focussed on younger cohorts (e.g., Fergusson et al. ${ }^{15}$ ) where cannabis use is more prevalent but the risk of stroke is low.

An unavoidable caveat in populationbased epidemiological surveys is reliance of self-report. However, self-reported stroke is sufficiently accurate for use in epidemiological studies with approximately $80 \%$ sensitivity and $99 \%$ specificity. ${ }^{16}$ Future epidemiological studies would, none-the-less, benefit from clinical confirmation of transient ischemic attack - the symptoms of which may be less familiar to the general population than those of stroke. The limitation of self-report is also countered by the large representative samples afforded by population cohort studies, an advantage which cannot be achieved in studies based on recorded cases of stroke or clinical case studies. In this study, we also relied on self-reported cannabis use, although self-report of illicit drug use is considered to be reliable when participant confidentiality is assured, ${ }^{17}$ as it was in this study.
An important limitation of this study is that we did not have a detailed history of participants' cannabis use, and therefore we could only correlate past year cannabis use with lifetime occurrence of stroke. However, onset of heavy cannabis use typically occurs in the late teens to early twenties ${ }^{18}$ and would therefore be likely to precede stroke in most cases. On the other hand, it is possible that a proportion of the non-cannabis using group may have had a past history of heavy cannabis use. This would lead to an underestimation of the relationship between cannabis use and stroke.

A further limitation was that we were unable to control for tobacco consumed concurrently with cannabis, family history of stroke/TIA, hyperlipidaemia, or other drug use (e.g., recreational stimulant use), all of which may have contributed to stroke risk among cannabis users. Illicit stimulant use is an important potential confound because it is a known risk factor for stroke and it tends to coalescence with heavy cannabis use. ${ }^{9}$ Another consideration is that several other covariates that we adjusted for may have mediated the relationship between cannabis use and stroke/TIA rather than being confounders (e.g. cannabis use is associated with worse education/vocational outcomes ${ }^{19}$ and heart problems, ${ }^{1}$ while frequent cannabis intoxication could plausibly reduce exercise levels). Contrary to previous research ${ }^{6}$ we did not find that heavy alcohol consumption was related to risk of stroke/TIA. This null finding may reflect the low levels of regular heavy drinking in the sample.

In conclusion, heavy cannabis users are a high risk group for stroke. Their cardiovascular function and other health risk behaviours for stroke should be monitored and managed accordingly. These findings reinforce the need to further investigate whether or not cannabis use is a causal risk factor for stroke. This possibility has important implications for the medicinal use of cannabis, as it may be contra-indicated for patients who are already at elevated stroke risk.

\section{Acknowledgements}

The study was supported by the NHMRC of Australia grant No. 179805. Kaarin Anstey is funded by NHMRC Fellowships No.1002560 and Nicolas Cherbuin by ARC Fellowship No. 12010227. The authors are grateful to Patricia Jacomb, Karen Maxwell, Peter Butterworth, Simon Easteal, Helen Christensen and the PATH interviewers.

\section{References}

1. Wolff V, Armspach J-P, Lauer V, Rouyer O, Bataillard M, Marescaux C, et al. Cannabis-related stroke: Myth or reality? Stroke. 2013;44(2):558-63.

2. United Nations Office on Drugs and Crime. World Drug Report 2013. New York (NY): UN; 2013.

3. Degenhardt L, Ferrari AJ, Calabria B, Hall WD, Norman $\mathrm{RE}, \mathrm{McGrath} J$, et al. The global epidemiology and contribution of cannabis use and dependence to the global burden of disease: Results from the GBD 2010 study. PLoS One. 2013;8(10):e76635.

4. Colliver JD, Compton WM, Gfroerer JC, Condon T. Projecting drug use among aging baby boomers in 2020. Ann Epidemiol. 2006;16(4):257-65.

5. Singh NN, Pan Y, Muengtaweeponsa S, Geller TJ, CruzFlores S. Cannabis-related stroke: Case series and review literature. J Stroke Cerebrovasc Dis. 2012;21(7):555-60.

6. Wolff V, Lauer V, Rouyer O, Sellal F, Meyer N, Raul JS, et al. Cannabis use, ischemic stroke, and multifocal intracranial vasoconstriction: A prospective study in 48 consecutiveyoung patients. Stroke. 2011;42(6):1778-80.

7. Jones RT. Cardiovascular system effects of marijuana.J Clin Pharmacol. 2002;42 Suppl 11:58-63.

8. Herning RI, BetterWE, Tate K, Cadet JL. Cerebrovascular perfusion in marijuana users during a month of monitored abstinence. Neurology. 2005;64(3):488-93.

9. Westover AN, McBride S, Haley RW. Stroke in young adults who abuse amphetamines or cocaine: A population-based study of hospitalized patients. Arch Gen Psychiatry. 2007;64(4):495-502.

10. Barber PA, Pridmore HM, Krishnamurthy V, Roberts $S$, Spriggs DA, Carter KN, et al. Cannabis, ischemic stroke, and transient ischemic attack: A case-control study. Stroke. 2013;44(8):2327-9.

11. Hillbom M. Alcohol consumption and stroke: Benefits and risks. Alcohol Clin Exp Res. 1998;22 Suppl 7:352-8.

12. Anstey KJ, Christensen H, Butterworth P, Easteal S, Mackinnon A, Jacomb T, et al. Cohort profile:The PATH through life project. Int JEpidemiol. 2012;41(4):951-60.

13. BaborTF, Higgins-Biddle JC, Saunders JB, Monteiro MG The Alcohol Use Disorders Identification Test: Guidelines for Use in Primary Care. Geneva (CHE): World Health Organization; 2001.

14. Petersen MR, Deddens JA. A comparison of two methods for estimating prevalence ratios. BMC Med Res Methodol. 2008:8:9.

15. Fergusson DM, Horwood LJ. Cannabis use and dependence in a New Zealand birth cohort. NZMed J. 2000;113(1109):156-8.

16. EngstadT,Bonaa KH,Viitanen M.Validity of self-reported stroke: The Tromso Study. Stroke. 2000;31(7):1602-7.

17. Darke S. Self-report among injecting drug users: A review. Drug Alcohol Depend. 1998:51(3):253-63 discussion 267-8.

18. Kessler RC, Berglund P, Demler O, Jin R, Merikangas $\mathrm{KR}$, Walters EE. Lifetime prevalence and age-of-onset distributions of DSM-IV disorders in the National Comorbidity Survey Replication. Arch Gen Psychiatry. 2005;62(6):593-602. Erratum in: Arch Gen Psychiatry. 2005;62(7):768. Merikangas, Kathleen R.

19. Horwood LJ, Fergusson DM, Hayatbakhsh MR Najman JM, Coffey C, Patton GC, et al. Cannabis use and educational achievement: Findings from three Australasian cohort studies. Drug Alcohol Depend. 2010;110(3):247-53. 